\title{
Internet of Things in Vehicle Safety - Obstacle Detection and Alert System
}

\author{
D.Umakirthika ${ }^{1}$, P.Pushparani ${ }^{2}$, M.Valan Rajkumar ${ }^{3}$ \\ ${ }^{1}$ Post-Graduate Scholar, Department of Electrical and Electronics Engineering, \\ Gnanamani College of Technology, Namakkal, Tamilnadu, India \\ ${ }^{2}$ Assistant Professor, Department of Electrical and Electronics Engineering, \\ Gnanamani College of Technology, Namakkal, Tamilnadu, India \\ ${ }^{3}$ Professor, Department of Electrical and Electronics Engineering, \\ Gnanamani College of Technology, Namakkal, Tamilnadu, India
}

\begin{abstract}
:
Recent development of the Internet of Things (IoT) and Smart Things provides an opportunity for the informationization for the automotive industry. This article describes Obstacle Detection and Alert System (ODAS) both incorporated as a single system for the obstacles such as speed breakers, barricades on the road using Internet of Things. Obstacle detection system uses in-built algorithm to detect an obstacle on the road using minimal vehicle parameters such as vehicle speed, steering angle. Obstacles locations thus marked by the detection system are stored locally and uploaded to cloud from time-to-time. Cloud server processes data from different vehicles and finalizes that there is a real obstacle at the particular location based on its own algorithm. Obstacles locations thus confirmed by the cloud server are downloaded to obstacle alert system from time-to-time, which alerts the driver about the obstacle on the road when the driver is nearing the location of the obstacle. This system also provides option to see obstacles location super-imposed on google maps so that user can plan his efficient route in advance. Existing systems only have road sign indications for obstacles such as speed breakers, barricades which the driver might not notice during driving, especially at night times. Existing google maps data do not have option to find road obstacles such as speed breakers, barricades information on it. The system aims to overcome these short-comings by a dedicated system which provides audible and visual alert about road obstacles.
\end{abstract}

Keywords: Internet of Things, Vehicle Data, Communication, Image processing, RADAR, Monitoring, Alert system, GPS module, Location information.

\section{Introduction}

The Internet of Things (IOT) is the network of physical devices, vehicles and other items embedded with electronics, software, sensors, actuators, and network connectivity which enable these objects to collect and exchange data. Each thing is uniquely identifiable through its embedded computing system but is able to interoperate within the existing Internet infrastructure [120].

The IOT allows objects to be sensed or controlled remotely across existing network infrastructure, creating opportunities for more direct integration of the physical world into computer-based systems, and resulting in improved efficiency, accuracy and economic benefit in addition to reduced human intervention [21-45]. When
IOT is augmented with sensors and actuators, the technology becomes an instance of the more general class of cyber-physical systems, which also encompasses technologies such as smart grids, virtual power plants, smart homes, intelligent transportation and smart cities. These devices collect useful data with the help of various existing technologies and then autonomously flow the data between other devices [4650]. The quick expansion of Internet-connected objects is also expected to generate large amounts of data from diverse locations, with the consequent necessity for quick aggregation of the data, and an increase in the need to index, store, and process such data more effectively. The ability to network embedded devices with limited CPU, memory and power resources means that IOT finds applications in nearly every field of power electronics and renewable energy [51-69]. 


\section{Obstacle Detection using Image Processing Technique}

Traffic sign recognition is a technology by which a vehicle is able to recognize the traffic signs put on the road e.g. speed limit or children or turn ahead. This is part of the features collectively called ADAS. The technology is being developed by many automotive suppliers. It uses Image processing techniques to detect the traffic signs. The detection methods can be generally divided into color based, shape based and learning based methods.

One of the basic use cases of a traffic sign recognition system is for speed limits. Most of the GPS data would procure speed information, but additional speed limit traffic signs can also be used to extract information and display it in the dashboard of the car to alert the driver about the road sign. This is an advanced driverassistance feature available in most high-end cars, mainly in European vehicles.

Modern traffic sign recognition systems are being developed using convolution neural networks, mainly driven by the requirements of autonomous vehicles and self-driving cars. In these scenarios, the detection system needs to identify a variety of traffic signs and not just speed limits. This is where the vienna convention on road signs and signals comes to help. A convolutional neural network can be trained to take in these predefined traffic signs and learn using deep learning techniques.

There are diverse algorithms for traffic sign recognition. Common ones are those based on the shape of the sign board. Typical sign board shapes like hexagons, circles, and rectangles define different types of signs, which can be used for classification. Other major algorithms for character recognition include haar-like features, freeman chain code, adaboost detection and deep learning neural networks methods. Haar-like features can be used to create cascaded classifiers which can then help detect the sign board characters.

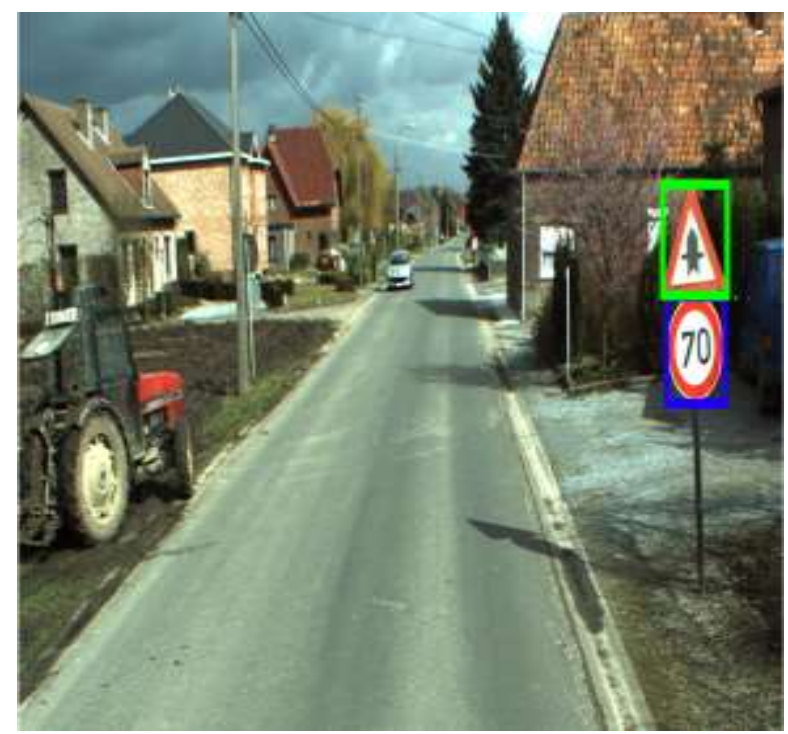

Figure 1: Traffic sign recognition using camera

Deep learning can be incorporated into traffic sign detection. Polygonal approximation of digital curves using Ramer-Douglas-Peucker algorithm can be used to detect the shape of the sign boards and methods like support vector machines and byte-mct with an ada boost classifier has been used in one of the methods to detect traffic signs.

\section{Obstacle Detection using Radar Technology}

RADAR (RAdio Detection And Ranging or RAdio Direction And Ranging) is an object-detection system that uses radio waves to determine the range, angle, or velocity of objects. It can be used to detect aircraft, ships, spacecraft, guided missiles, motor vehicles, weather formations, and terrain. A radar system consists of a transmitter producing electromagnetic waves in the radio or microwaves domain, a transmitting antenna, a receiving antenna (often the same antenna is used for transmitting and receiving) and a receiver and processor to determine properties of the object. Radio waves from the transmitter reflect off the object and return to the receiver, giving information about the object's location and speed. 


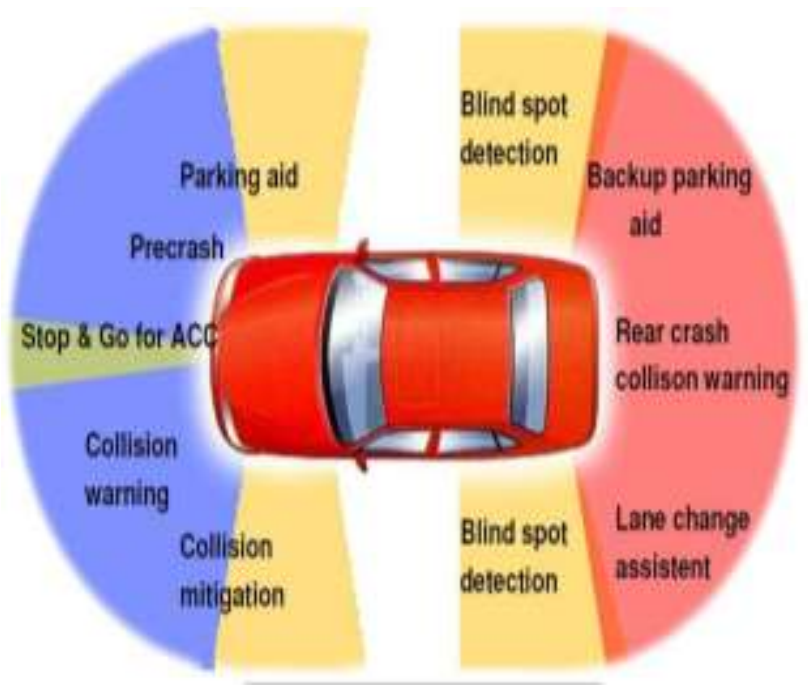

Figure 2: Application of RADAR in Cars

\section{Alert system for Drivers in Vehicles}

Vibration alert is made to the driver by using Steering Wheel. On the detection of obstacle or any other scenarios that require driver attention, steering wheel vibration is used to get the attention of the driver. Steering wheel vibration is achieved by fast rotation of steering in opposite sides which look like steering vibration.

Audible alert is given to the driver by means of a buzzer. On the detection of obstacle or any other scenarios that require driver attention, audible alert is used to get the attention of the driver. Based on the frequency of the alert, the driver is notified about the obstacle range and the urgency of the driver to interrupt. Audible alert does not give any information on the cause and it only alerts the driver that there is something that needs his attention.

Visual alert is provided to the driver by means of LCD display. Visual alert alerts the driver about possible information that needs driver attention. Usually Audible alert is combined with visual alert to grab the attention of the driver. Visual alert provides more information about exact nature of driver attention by means of visual indication.

\section{Location Detection Systems}

\subsection{Global Positioning System}

The Global Positioning System is a space-based radio navigation system owned by the United States government and operated by the United States Air Force. It is a global navigation satellite system that provides geo-location and time information to a GPS receiver anywhere on or near the earth where there is an unobstructed line of sight to four or more GPS satellites.

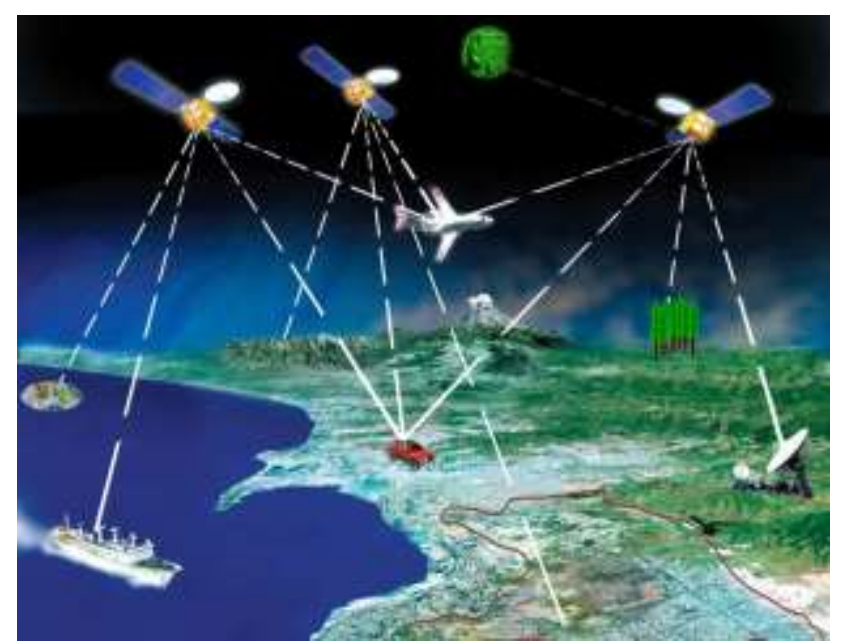

Figure 3: Operations of GPS

The GPS system does not require the user to transmit any data, and it operates independently of any telephonic or internet reception, though these technologies can enhance the usefulness of the GPS positioning information. The GPS system provides critical positioning capabilities to military, civil, and commercial users around the world. The United States government created the system, maintains it, and makes it freely accessible to anyone with a GPS receiver.

\subsection{Global Navigation Satellite System}

Global Navigation Satellite System is a space-based satellite navigation system operating in the radio navigation-satellite service. It provides an alternative to GPS and is the second navigational system in operation with global coverage and of comparable precision.

Manufacturers of GPS devices say that adding global navigation satellite system made more satellites available to them, meaning positions can be fixed more quickly and accurately, especially in built-up areas where the view to some GPS satellites is obscured by buildings. Satellites will be equipped with a transponder which will relay distress signals from emergency beacons to the rescue coordination centre, which will then initiate a rescue operation. At the same time, the system is projected to provide a signal, the return link message, to the emergency beacon, informing them that their situation has been detected and help is on the way. This latter feature is new and is considered a major upgrade compared to the existing cospas-sarsat system, which does not provide feedback to the user. 


\section{Vehicle Bus Network}

A vehicle bus is a specialized internal communications network that interconnects components inside a vehicle. Special requirements for vehicle control such as assurance of message delivery, of non-conflicting messages, of minimum time of delivery, of low cost, and of emf noise resilience, as well as redundant routing and other characteristics mandate the use of less common networking protocols. Protocols include Controller Area Network, Local Interconnect Network and others.

With stringent emission standards for automobiles, it became impossible to attain the required degree of control without the help of on-board computing devices. On-board electronic devices have also contributed substantially to vehicle performance, occupant comfort, ease of manufacture and cost effectiveness. At one time, a car radio was likely the only electronic device in an automobile, but now almost every component of the vehicle has some electronic feature. Typical electronic modules on today's vehicles include the Engine Control Unit, the Transmission Control Unit, the Anti-lock Braking System and body control modules.

An electronic control module typically gets its input from sensors that it uses in its computation. Various actuators are used to enforce the actions determined by the module. The modules need to exchange data among themselves during the normal operation of the vehicle. For example, the engine needs to tell the transmission what the engine speed is, and the transmission needs to tell other modules when a gear shift occurs. This need to exchange data quickly and reliably led to the development of the vehicle network, as the medium of data exchange.

The automotive industry quickly realized the complexity of wiring each module to every other module. Such a wiring design would not only be complex, it would have to be altered depending on which modules were included in the specific vehicle. For example, a car without the anti-lock brake module would have to be wired differently than one that included anti-lock brakes.

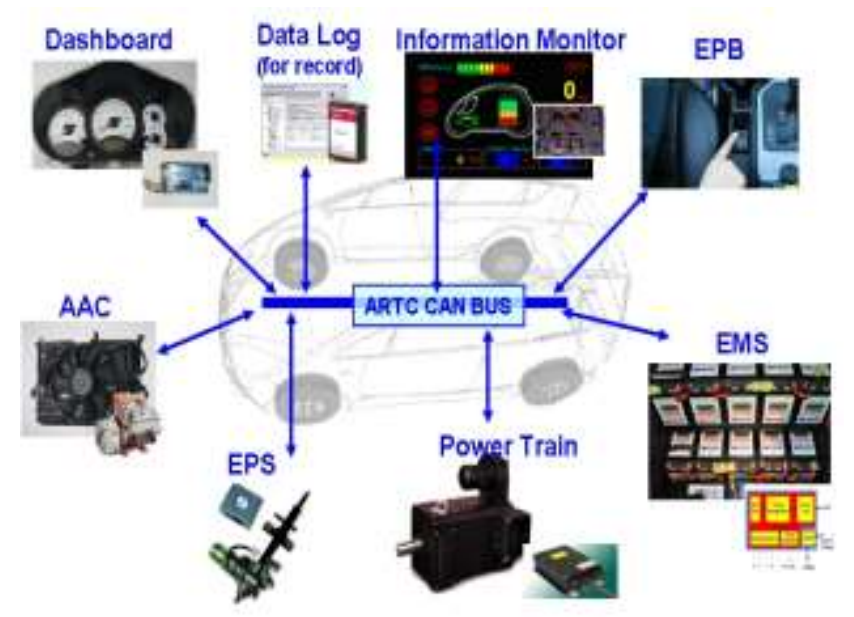

Figure 4: Vehicle Bus Network

The industry's answer to this problem was to create a central network in the vehicle. Modules could be plugged into the network and would be able to communicate with any other module that was installed on the network. This design was easier to manufacture, easier to maintain and provided the flexibility to add and remove options without affecting the entire vehicle's wiring architecture. Each module, a node on the vehicle network, controls specific components related to its function and communicates with the other modules as necessary, using a standard protocol, over the vehicle network.

Although the vehicle network made modest demands on data throughput, the demand for more on-board computing is continuing to drive changes to these networks to provide higher-speed communication between modules. The control area network includes the receiver and transmitter for the host to controller transmission and interlinking between the computers.

\section{Obstacle Detection and Alert System Requirements}

Obstacle detection and alert system is a combined embedded system having algorithms to detect obstacles and also alert the driver with pre-stored obstacle data. ODAS is an additional system that will be fitted in the vehicle.

ODAS in vehicle consists of following components:

- Controller

- CAN Transceiver

- LCD Display

- Buzzer

- GPS Module

- GPRS Module 


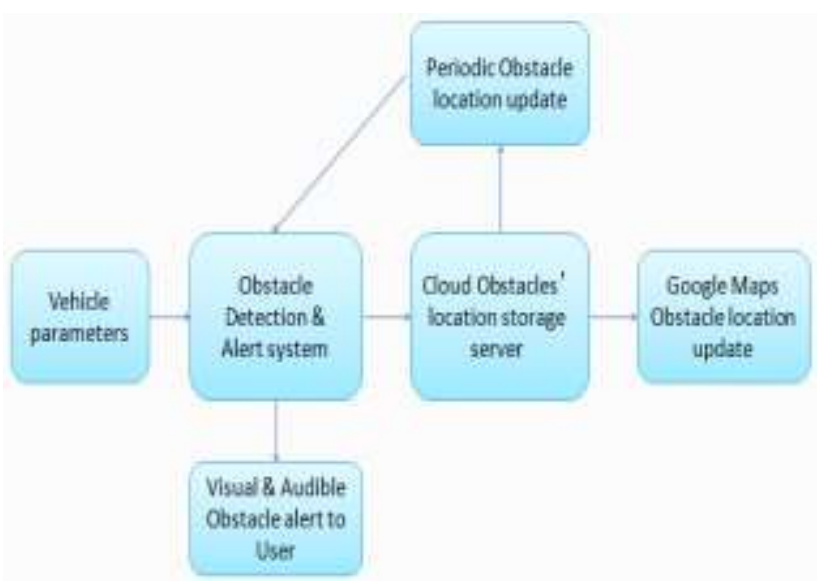

Figure 5: Overview of ODAS

\section{ODAS - Detection System}

\subsection{Probable obstacle detection}

ODAS Detection system has the responsibility to detect obstacles such as speed breakers, barricades, and potholes on the road by pre-defined algorithm. It detects probable obstacle locations by using vehicle parameters as input and by using in-built detection algorithm. It uses two vehicle parameters as major inputs

- Vehicle Speed

- Steering Angle

Conditions for Obstacle detection (speed breakers, potholes) are as follows:

- Vehicle speed falls from above $40 \mathrm{~km} / \mathrm{h}$ to below $20 \mathrm{~km} / \mathrm{h}$ within definite time (say 10seconds)

- Vehicle speed rises above $40 \mathrm{~km} / \mathrm{h}$ from below $20 \mathrm{~km} / \mathrm{h}$ within definite time (say 20seconds)

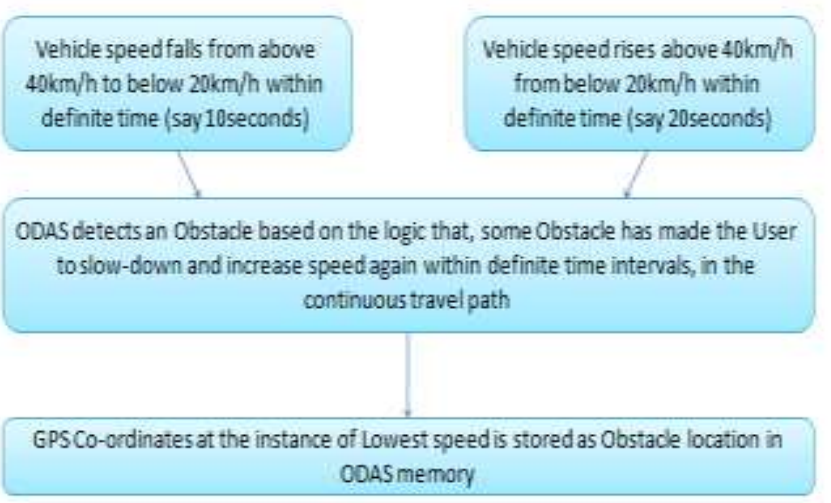

Figure 6: ODAS speed breaker detection method

If the above conditions of detection algorithm satisfy, then ODAS detection system concludes that there was speed breaker/pothole in the path, based on the logic that, speed breaker/pothole has made the user to slow-

down and increase speed again within definite time intervals, in the continuous travel path.

GPS Co-ordinates from GPS Module at the instance of lowest speed is stored as speed breaker/pothole location in ODAS memory

Conditions for obstacle detection (Barricades) are as follows:

- Vehicle speed falls from above $40 \mathrm{~km} / \mathrm{h}$ to below $20 \mathrm{~km} / \mathrm{h}$ within definite time (say 10 seconds)

- Steering angle changes from Center -> Positive -> Center -> Negative or vice versa

- Vehicle speed rises above $40 \mathrm{~km} / \mathrm{h}$ from below $20 \mathrm{~km} / \mathrm{h}$ within definite time (say 20 seconds)

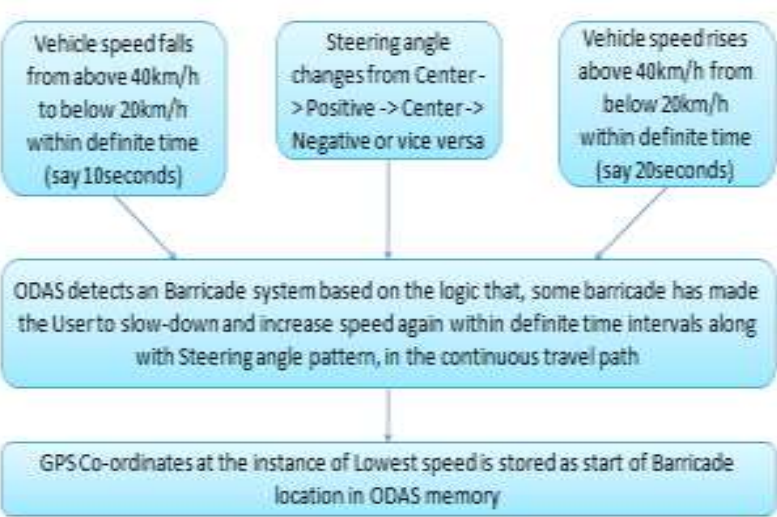

Figure 7: ODAS barricade detection method If the above conditions of detection algorithm satisfy, then ODAS detection system concludes that there was barricade in the path, based on the logic that, barricade has made the user to slow-down, steer opposite sides and increase speed again within definite time intervals, in the continuous travel path. GPS co-ordinates from GPS Module at the instance of lowest speed is stored as barricade location in ODAS memory.

\subsection{Upload to Cloud Server}

Obstacle locations that are GPS co-ordinates that are stored in ODAS memory are uploaded to cloud server from time-to-time using IOT infrastructure.

\subsection{Obstacle Detection Cloud Server}

Obstacle detection cloud server forms a important part of ODAS system. It receives all the obstacles locations that are detected by individual ODAS systems installed in vehicles via IOT infrastructure.

The cloud server has the following functions 
- Receive and store obstacles location from individual ODAS

- Consolidate and group closer GPS co-ordinates of obstacles

The cloud server determines that there is actually an obstacle on the road using the GPS co-ordinates with difference of 0.001 differences exceeds 10 instances. If the condition is satisfied, then the average of the 10 GPS co-ordinates is stored as obstacle location in cloud server.

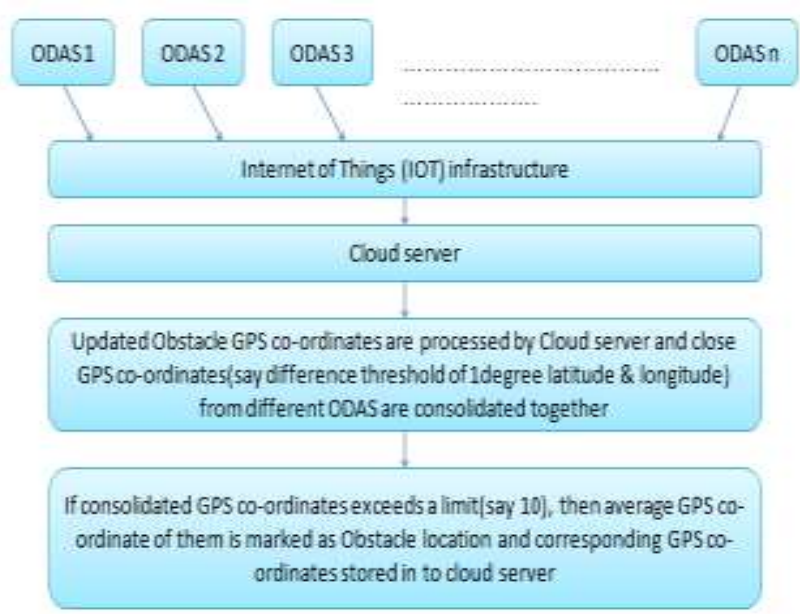

Figure 8: Cloud server

\section{ODAS - Alert System}

\subsection{Download from cloud server}

Obstacle locations thus consolidated in the cloud server are updated to ODAS in individual vehicles by means of Internet-of-Things (IOT) infrastructure from time-totime.

Obstacles location GPS co-ordinates are pushed to individual ODAS upon request which happens periodically. GPS co-ordinates thus received are stored in ODAS memory as obstacles locations, which are used to alert the driver about the obstacles.

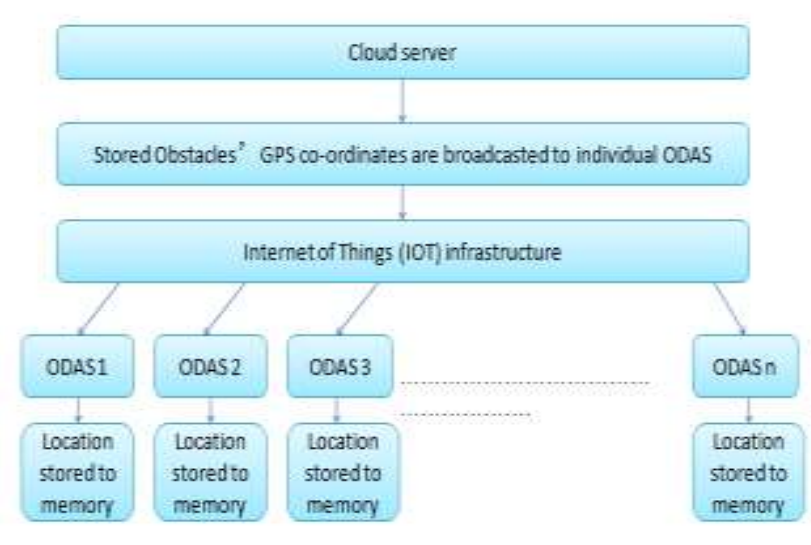

Figure 9: Obstacles location download

\subsection{Obstacle Alert}

Obstacles locations received from cloud server are used to alert the driver about nearby obstacles on his path. Current GPS co-ordinates from GPS module are compared continuously with obstacles GPS coordinates when the vehicle is in travel.

If the current GPS co-ordinates are closer to any of the pre-stored obstacles GPS co-ordinates in ODAS Memory, then an alert is given to the user.

Alert from ODAS is of two types

- Audible alert

- Visual alert

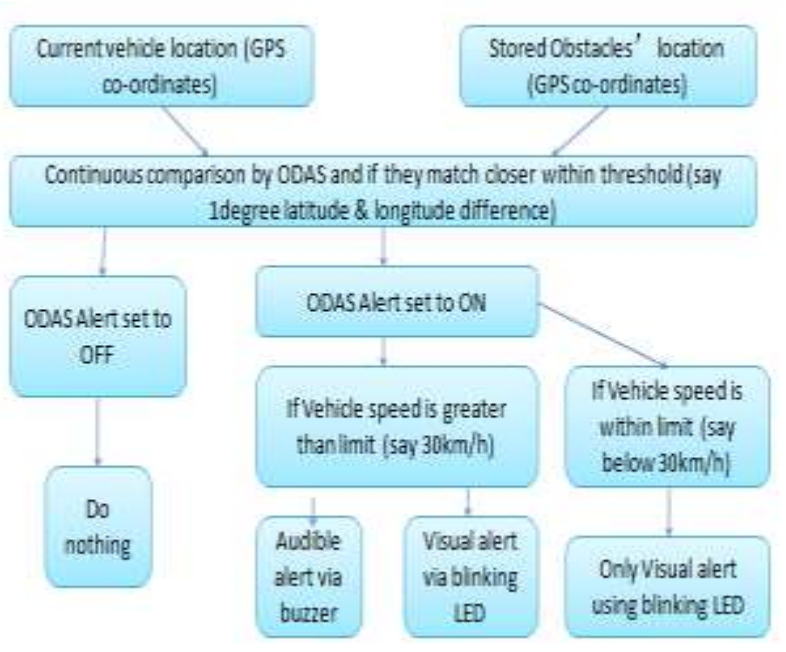

Figure 10: ODAS Alert system

If the vehicle speed is within lowest set limit, then ODAS understands that user has already noticed the obstacle and is going slow. Only visual alert is given to the user in that case. If the vehicle speed is above the lowest limit, then ODAS alert the user about obstacle with audible as well as visual alerts. ODAS can be 
switched off from giving alerts as and when needed.

\subsubsection{Audible Alert}

ODAS provides audible alert to the user by means of buzzer connected to ODAS. Buzzer frequency depends upon the current speed of the vehicle above the threshold limit on nearing the obstacle location.

- If the vehicle speed is much higher than the threshold limit, then frequency of buzzer is set high so that user understands that he needs to slow down immediately.

- If the vehicle speed is only slightly higher than threshold limit, then frequency of buzzer is kept less, because user may already be slowing down seeing obstacle.

\subsubsection{Visual Alert}

ODAS provides visual alert to the user by means blinking LED lights. Similar to audible alert, the frequency of blinking depends upon vehicle speed above threshold limit.

- If the vehicle speed is much higher than the threshold limit, then frequency of blinking LED is set high

- If the vehicle speed is only slightly higher than threshold limit, then frequency of LED blinking is kept less.

\section{Obstacles update to Google maps}

Obstacles locations, basically GPS co-ordinates available in cloud server are not just sent to individual ODAS in vehicles. They are also used to show the obstacles location on top of Google Maps of the end user. This is achieved by making use of in-built Google Maps feature called "Places List".

\subsection{Google Maps Places List}

Google Maps has an in-built feature called "Places List". It allows the user to store desired locations (GPS coordinates) of the map in to memory as a list. This stored list of Places is available on top of Google Maps for the user, which can be revisited by a single click. User has the option to add, delete, and edit the stored places. In the Google Maps app, you can create a list of places, like your favorite places or places you want to visit.

\subsection{Google Maps places list sharing}

Google Maps allow the places list to be shared with other users via a link. The other users on receiving the link can follow them and updates in the list will be visible to all users who follow the list. As "Places List" can be shared and followed, we make use of the option to share obstacles locations to users who have installed ODAS in their vehicles. Google Maps "Places list" are associated to a Google account.

Since "Places List" is associated to Google account, cloud server shall have a Google account and "Places List" created for storing obstacles locations on the list. Users who have ODAS installed are shared the "Places List" link. Users can follow the "Places List" that is shared to them to get updates on the obstacles location on top of their Google Maps.

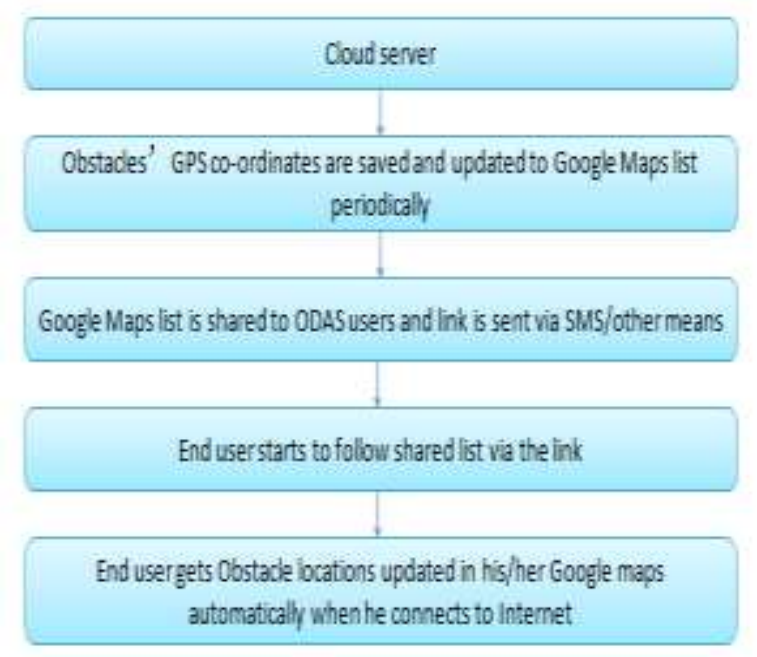

Figure 11: Obstacles location update to Google Maps

Cloud server will update obstacles location list periodically based on the data it receives from individual ODAS. Cloud server can have multiple lists for each obstacle and also separate lists for each region which the user can follow in his own device using his Google account.

\section{Conclusion}

The Obstacle Detection and Alert System (ODAS) uses readily available Vehicle parameters such as Vehicle Speed, Steering angle along with GPS Module helps to detect the Obstacles on Road. By a centralized Cloud server, the actual Obstacles' GPS locations are marked by making use of data from different ODAS systems, which makes it a reliable system. ODAS alert helps in avoiding Road mishaps by alerting the driver to reduce his speed to safe Vehicle speed before encountering the Obstacles. Update of Obstacles location in End-user 
Google Maps helps the user to plan his/her efficient route for travel in advance.

\section{References}

[1] M.Afrin, M.R.Mahmud and M.A.Razzaque (2015), "Real time detection of speed breakers and warning system for on-road drivers," IEEE International WIE Conference on Electrical and Computer Engineering, Dhaka, pp. 495-498.

[2] M.A.Al Rashed, O.A.Oumar and D.Singh (2013), "A real time GSM/GPS based tracking system based on GSM mobile phone," Second International Conference on Future Generation Communication Technologies, London, pp. 65-68.

[3] R.Ramani, S.Valarmathy, N.SuthanthiraVanitha, S.Selvaraju, and M.Thiruppathi (2013), "Vehicle Tracking and Locking Sytem Based on GSM and GPS", I.J. Intelligent Systems and Applications, Vol. 9, pp. 86-93.

[4] N. Abbani, M. Jomaa, T. Tarhini, H. Artail, and W. El-Hajj, "Managing social networks in vehicular networks using trust rules," in Proc. IEEE Symp. Wireless Technol. Appl., Sep. 2011, pp. 168-173.

[5] M.ValanRajkumar, P.S.Manoharan, Modeling and Simulation of Three-phase DCMLI using SVPWM for Photovoltaic System, Springer Lecture Notes in Electrical Engineering, under the volume titled "Power Electronics \& Renewable Energy Systems", Volume 326, Chapter No 5, January 2015, Pages 39-45.

[6] M.ValanRajkumar, P.S.Manoharan, Harmonic Reduction of Fuzzy PI Controller based ThreePhase Seven-level DCMLI with SVPWM for Grid Connected Photovoltaic System, Journal International Review on Modeling and Simulations, Volume 6, No 3, June 2013, Pages 684-692.

[7] A.Ravi, P.S.Manoharan, M.ValanRajkumar, "Harmonic Reduction of Three-Phase Multilevel Inverter for Grid connected Photovoltaic System using Closed Loop Switching Control", JournalIREMOS, Volume 5, No 5, October 2012, Pages 1934-1942. ISSN: 1974-9821 (Print), 1974982X (Online)

[8] Ambade Shruti Dinker and S.A Shaikh (2011), "Design and Implementation Of vehicle Tracking System Using GPS”, Joural of Information Engineering and Applications, Vol 1, No.3.

[9] P.Thirumurugan, P.S.Manoharan, M.ValanRajkumar, "VLSI Based Inverter
Switching Control" in the proceedings of International Conference on Mathematical Modeling and Applied Soft Computing MMASC'12 - Coimbatore Institute of Technology on July 2012, Vol-2 (Page):965-973.

[10]C.Hemalatha, M.Valan Rajkumar, G.Vidhya Krishnan, "Simulation and Analysis for MPPT Control with Modified firefly algorithm for photovoltaic system", International Journal of Innovative Studies in Sciences and Engineering Technology, Volume 2, No 11, Nov.2016, Pages 48-52.

[11]M.Jain, A.P.Singh, S.Bali, and S.Kaul (2012), "Speed-Breaker Early Warning System," in Proceedings of the 6th USENIX/ACM Workshop on Networked Systems for Developing Regions, New York, USA.

[12] G.Vidhya Krishnan, M.Valan Rajkumar, C.Hemalatha, "Modeling and Simulation of 13-level Cascaded Hybrid Multilevel Inverter with less number of Switches", International Journal of Innovative Studies in Sciences and Engineering Technology, Volume 2, No 11, Nov.2016, Pages 43-47.

[13] Y. Musa, J. Wang (2012), "Vehicle Tracking and Anti-theft System using GPSGSM“, International Journal of Engineering Research \& Technology, Vol. 1 Issue 10.

[14] M.ValanRajkumar, P.S.Manoharan, FPGA Based Multilevel Cascaded Inverters with SVPWM Algorithm for Photovoltaic system, Elsevier Journal Solar Energy, Volume 87, Issue 1, January 2013, Pages 229-245.

[15] M.ValanRajkumar, P.S.Manoharan, Space Vector Pulse Width Modulation of Three-Phase DCMLI with Neuro-Fuzzy MPPT for Photovoltaic System, World Journal of Modelling and Simulation, Volume 10, No 3, August 2014, Pages 193-205.

[16] Mansour Mohseni, and Syed M. Islam, "A New Vector-Based Hysteresis Current Control Scheme for Three-Phase PWM Voltage-Source Inverters", IEEE Transactions on Power Systems, vol.25,No.9,September-2010.

[17] M.Valan Rajkumar, Prakasam, P. and Manoharan, P.S. (2016) Investigational Validation of PV Based DCDMLI Using Simplified SVM Algorithm Utilizing FPGA Tied with Independent Sources. Circuits and Systems, Volume 7, No 11, 38313848. http://dx.doi.org/10.4236/cs.2016.711320 
[18]P.Thirumurugan,

P.S.Manoharan, M.ValanRajkumar, VLSI Based Space Vector Pulse Width Modulation Switching Control in the proceedings of IEEE International Conference on Advanced Communication Control and Computing Technologies ICACCCT 2012 on August 2012, ISBN No. 978-1-4673-2045-0 (Print) (Page):366-370.

[19] M.ValanRajkumar, P.S.Manoharan, "Modeling, Simulation and Harmonic Reduction of ThreePhase Multilevel Cascaded Inverters with SVPWM for Photovoltaic System", Journal International Review on Modeling and Simulations, Volume 6, No. 2, April 2013, Pages 342-350. ISSN: 19749821 (Print), 1974-982X (Online)

[20]Carlos Henrique da Silva, Rondineli R. Pereira, Luiz Eduardo Borges da Silva, Germano LambertTorres, João Onofre Pereira Pinto, and Se Un Ahn, "Dead-Time Compensation in Shunt Active Power Filters Using Fast Feedback Loop" IEEE conference, 2008.

[21]M.Valan Rajkumar, G.Ranjhitha, M.Pradeep, Mohammad Fasil PK, R.Sathishkumar, "Fuzzy based Speed Control of Brushless DC Motor fed Electric Vehicle", International Journal of Innovative Studies in Sciences and Engineering Technology (IJISSET), Volume: 3, Issue: 3, March 2017, Pages 12-17. ISSN: 2455-4863 (Online).

[22] M.Valan Rajkumar, J.Chandramohan, D.Aravind, M.Basker, "Performances Analysis of Power Factor Correction for PWM Control based Bridgeless Cuk Rectifier with Positive Output Voltage", International Journal of Emerging Technologies in Engineering Research (IJETER), Volume: 5, Issue: 4, April 2017, Pages 116-121. ISSN: 2454-6410 (Online).

[23] K.Aswini, K.Nandhini, SR.Nandhini, G.Akalya, B.Rajeshkumar, M.Valan Rajkumar, "Simulation and Analysis of ASCAD Multilevel Inverter with SPWM for Photovoltaic System", International Journal of Innovative Studies in Sciences and Engineering Technology (IJISSET), Volume: 3, Issue: 4, April 2017, Pages 1-9. ISSN: 2455-4863 (Online).

[24] M.Jalaluddin, M.Jabeen, D.Vijayalakshmi (2012), "Service-Oriented Architecture based Global Positioning System", IOSR Journal of Engineering, Volume 2, Issue 10, PP 09-13.

$\begin{array}{cr}\text { [25] M.Valan Rajkumar, } & \text { M.Mahakumar, } \\ \text { M.Manojkumar, M.Hemaraj, } & \text { E.Kumaravel, }\end{array}$
"Modelling and Analysis of DC-DC Converter with Various MPPT Algorithms for PV System", International Journal of Innovative Studies in Sciences and Engineering Technology (IJISSET), Volume: 3, Issue: 4, April 2017, Pages 17-22. ISSN: 2455-4863 (Online).

[26] M.Valan Rajkumar, T.Indumathi, “Analysis of Low Power Multi-core Embedded Management for Energy Harvesting", IOSR-Journal of Electrical and Electronics Engineering, Volume 12, Issue 2, Ver. II, March-April 2017, Pages 25-33. ISSN: 23203331 (Print) 2278-1676 (Online).

[27]A.Ravi, M.Valan Rajkumar, P.S.Manoharan, "Harmonic Reduction of Three-Phase Eleven-level DCMLI with Fuzzy MPPT for Grid Connected Photovoltaic System", International Journal of Applied Engineering Research (IJAER), Volume 10, No 2, 2015, Pages 3251-3268. ISSN: 09734562 (Print).

[28] M.Valan Rajkumar, J.Karthikeyan, P.S.Manoharan, "Modeling and Simulation of Multiphase DCMLI with SVPWM for Photovoltaic System", International Journal of Applied Engineering Research(IJAER), Special Issue: Volume 9, No 24, 2014, Pages 8477-8483. ISSN: 0973-4562 (Print).

[29] M.Soytürk, F.Doğan, E.Şaşmaz and Ş.Böyük (2014), "Detection and analysis of holes and bumps on road surfaces", 2014 22nd Signal Processing and Communications Applications Conference, Trabzon, pp. 1897-1901.

[30] L. Atzori, A. Iera, G. Morabito, and M. Nitti, "The social Internet of Things (SIoT)-When social networks meet the Internet of Things: Concept, architecture and network characterization," Comput. Netw., vol. 56, no. 16, pp.3594-3608, Nov. 2012.

[31]M.ValanRajkumar, P.S.Manoharan, "Modeling and Simulation of Five-level Five-phase Voltage Source Inverter for Photovoltaic Systems", Journal PrzegladElektrotechniczny, Volume 10, No. 10, October 2013, Pages 237-241. ISSN: 0033-2097 (Print)

[32]M.Valan Rajkumar, P.S.Manoharan, A.Ravi, "Simulation and an Experimental Investigation of SVPWM Technique on a Multilevel Voltage Source Inverter for Photovoltaic Systems", Elsevier International Journal of Electrical Power and Energy Systems, Volume 52, Issue 9, November 
2013, Pages 116-131. ISSN: 0142-0615 (Print), 1879-3517 (Online)

[33] SR.Nandhini, G.Akalya, K.Aswini, K.Nandhini, M.Valan Rajkumar, B.Rajeshkumar, "A New Topology of H-bridge based Multilevel Inverter for PV System with Reduced Switches", International Journal of Emerging Technologies in Engineering Research (IJETER), Volume: 5, Issue: 4, April 2017, Pages 60-68. ISSN: 2454-6410 (Online).

[34] M.Valan Rajkumar, M.Mahakumar, M.Manojkumar, M.Hemaraj, E.Kumaravel, "A New DC-DC Converter Topology with Grey Wolf MPPT Algorithm for Photovoltaic System", International Journal of Emerging Technologies in Engineering Research (IJETER), Volume: 5, Issue: 4, April 2017, Pages 54-59. ISSN: 2454-6410 (Online).

[35] L.Malliga, K.Bommannaraja, M.Valan Rajkumar, 'Investigation of FCM based Image RetrievelSegmentation on Human Computational Intelligent Systems", International Journal of Applied Engineering Research (IJAER), Special Issue: Volume 10, No 12, 2015, Pages 10769-10774. ISSN: 0973-4562 (Print).

[36] M.Desai and A.Phadke (2017), "Internet of Things based vehicle monitoring system," Fourteenth International Conference on Wireless and Optical Communications Networks, Mumbai, India, pp. 13.

[37] U.Suresh Kumar, P.S.Manoharan, M.Valan Rajkumar, "Feasibility Sensitivity Analysis in Potential Area for Standalone Hybrid Renewable Energy in Tamil Nadu, India”, Applied Mechanics and Materials Journal, under the volume titled "Advancements in Automation and Control Technologies", Volume 573, June 2014, Pages 757-766. ISSN: 1660-9336 (Print), ISBN13: 978-3-03835-124-5 (Online).

[38] C.Hemalatha, M.Valan Rajkumar, M.Gayathri, "IOT Based Building Monitoring System Using GSM Technique", IOSR-Journal of Electronics and Communication Engineering (IOSR-JECE), Volume 12, Issue 2, Ver. III, March-April 2017, Pages 68-75. ISSN: 2278-8735 (Print) 22782834 (Online).

[39] S. Lee, G. Tewolde and J. Kwon (2014), "Design and implementation of vehicle tracking system using GPS/GSM/GPRS technology and smartphone application," IEEE World Forum on Internet of Things, Seoul, pp. 353-358.
[40] Mohammad A. Al-Khedher (2011), "Hybrid GPS-GSM Localization of Automobile Tracking System", International Journal of Computer Science \& Information Technology, Vol 3, No 6, Dec 2011.

[41]S.Rashini, P.S.Manoharan, M.Valan Rajkumar, "Interfacing PV system to the Utility Grid using a Voltage Source Inverter", Journal of Emerging Technologies Electrical Engineering, Special IssueICBDM 2013, Volume 1, No 1, March 2013, Pages 124-129. ISSN: 0973-2993 (Print)

[42] S.Sathyaraj, M.Valan Rajkumar, J.Chandramohan, "Modeling and Simulation of Asymmetric Cascaded Multilevel Inverter with Reduced Switches using Multicarrier PWM Control", International Journal of Advanced Research in Electrical, Electronics and Instrumentation Engineering (IJAREEIE), Volume 5, Issue 10, October 2016, Pages 8064-8071. ISSN: 23203765 (Print), 2278-8875 (Online)

[43] G.Ranjhitha, M.Valan Rajkumar, 'Implementation of Genetic Algorithm based Maximum Power Point Tracking for Photovoltaic System”, International Journal of Innovative Research in Science, Engineering and Technology (IJIRSET), Volume 5, Issue 11, November 2016, Pages 18860-18868. ISSN: 2347-6710 (Print), 2319-8753 (Online)

[44]S.Sathishkumar, M.Valan Rajkumar, R.Yuvaraj, "Modeling and Analysis of Soft-Switched Interleaved Boost Converter for Photovoltaic System", International Journal for Science and Advance Research in Technology (IJSART), Volume 2, Issue 11, November 2016, Pages 4348. ISSN: 2395-1052 (Online)

[45] M.Sundaraperumal, M.Valan Rajkumar, A.Venkatesh, "Modeling and Analysis of Current Source Multilevel Inverter using PI Controllers with Multicarrier PWM Technique", International Journal for Science and Advance Research in Technology (IJSART), Volume 2, Issue 11, November 2016, Pages 275-280. ISSN: 23951052 (Online)

[46]R.Yuvaraj, S.Sathishkumar, M.Valan Rajkumar, "Analysis of PV based Soft Switching Boost DCDC Converter with Zero Current Switching Technique", International Journal of Advanced Research in Management, Architecture, Technology and Engineering (IJARMATE), Volume 2, Issue 12, December 2016 Pages 1-5. ISSN: 2454-9762 (Print) 2454-9762 (Online) 
[47] M.Valan

Rajkumar,

M.Mahakumar, M.Manojkumar, M.Hemaraj, E.Kumaravel, "A New MPPT design using Grey Wolf Optimization Techniques with DC-DC Converter for PV System", International Journal for Science and Advance Research in Technology (IJSART), Volume 3, Issue 3, March 2017, Pages 829-835. ISSN: 2395-1052 (Online)

[48] K.Nandhini, SR.Nandhini, G.Akalya, K.Aswini, M.Valan Rajkumar, B.Rajeshkumar, 'Implementation of 21-level Asymmetrical Cascaded Multilevel Inverter with Reducing Number of Switches", International Journal for Science and Advance Research in Technology (IJSART), Volume 3, Issue 3, March 2017, Pages 809-818. ISSN: 2395-1052 (Online)

[49] E. Biddlecombe, 'UN predicts 'internet of things',' July 6,2009.

[50] K. M. Alam, M. Saini, and A. El Saddik, 'tNote: A social network of vehicles under Internet of Things," in Internet of Vehicles_Technologies and Services. Berlin, Germany: Springer-Verlag, 2014, pp. 227-236.

[51] S.Sathishkumar, M.Valan Rajkumar, S.Vinothkumar, M.Maruthamuthu, A.Sounder, A.Kumaresan, "A New Design for DC-DC Converter Topology with MISO for Renewable Energy Resources", International Journal of Emerging Technologies in Engineering Research (IJETER), Volume: 5, Issue: 4, April 2017, Pages 143-149. ISSN: 2454-6410 (Online)

[52] M.Valan Rajkumar, M.Mahakumar, M.Manojkumar, M.Hemaraj, E.Kumaravel, "Implementation of Various MPPT Algorithms with SEPIC Converter for PV System", International Journal of Engineering Research \& TechnologySpecial Issue 2017, Volume 5, Issue 13, 2017, Pages 589-593. ISSN: 2278-0181 (Print)

[53] G.Akalya, K.Aswini, K.Nandhini, SR.Nandhini, M.Valan Rajkumar, B.Rajeshkumar, "Modelling and Analysis of Multilevel Inverter for Photovoltaic System", International Journal of Advanced Research Methodology in Engineering \& Technology (IJARMET), Volume 1, Issue 3, May 2017, Pages 36-43. ISSN: 2456-6446 (Online)

[54] Mohammad Fasail PK, M.Pradeep, R.Sathishkumar, G.Ranjhitha, M.Valan Rajkumar, 'Speed Control BLDC Motor using Fuzzy Logic and PID Controller fed Electric Vehicle", South Asian Journal of Engineering and Technology,
Volume 3, Issue 3, March 2017, Pages 118-131. ISSN: 2454-9614 (Print)

[55] Y. Hao, Z. Fang, Z. Yanjun, L. Yu, Z. Wenda, C. Wenjie, and L. Jinjun, "A Source-CurrentDetected Shunt Active Power Filter Control Scheme Based on Vector Resonant Controller," Industry Applications, IEEE Transactions on, vol. 50, no. 3, pp. 1953-1965, 2014.

[56] G.Vidhya Krishnan, M.Valan Rajkumar, D.Umakirthika, "Role of Internet of Things in Smart Passenger Cars", International Journal of Engineering And Computer Science (IJECS), Volume: 6, Issue: 5, May 2017, Pages 2141021417. ISSN: 2319-7242 (Online).

[57]M.Valan Rajkumar, T.Indumathi, "Performance Analysis of PV based Low Power Multi-Core Embedded Management using Wireless Communication System", International Journal of Emerging Technologies in Engineering Research (IJETER), Volume: 5, Issue: 5, May 2017, Pages 129-136. ISSN: 2454-6410 (Online).

[58]C.Hemalatha, M.Valan Rajkumar, M.Gayathri, "Performance Analysis of IoT based Secured Smart Building Monitoring System Interface using GSM Technique", International Journal of Emerging Technologies in Engineering Research (IJETER), Volume: 5, Issue: 5, May 2017, Pages 141-147. ISSN: 2454-6410 (Online).

[59]Rode, S.S.ve diğerleri (2009), 'Pothole Detection and Warning System: Infrastructure Support and System Design", International Conference on Electronic Computer Technology, pp.286-290.

[60] Tsai (2012), "Critical Assessment of Detecting Asphalt Pavement Cracks under Different Lighting and Low Intensity Contrast Conditions Using Emerging 3D Laser Technology". Journal of Transportation Engineering, 138(5), pp. 649-656.

[61] L. Atzori, A. Iera, and G. Morabito, "SIoT: Giving a social structure to the Internet of Things," IEEE Commun.Lett., vol. 15, no. 11, pp. 11931195, Nov. 2011.

[62]P.Pushparani, M.Valan Rajkumar, R.Suganya, "Simulation and Analysis of SVHM Technique for DCMLI under Transient Conditions with NonLinear Loads", International Journal of Emerging Technologies in Engineering Research (IJETER), Volume: 5, Issue: 11, November 2017, Pages 9096. ISSN: 2454-6410 (Online).

[63]R.Suganya, M.Valan Rajkumar, P.Pushparani, "Simulation and Analysis of Boost Converter with 
MPPT for PV System using Chaos PSO Algorithm", International Journal of Emerging Technologies in Engineering Research (IJETER), Volume: 5, Issue: 11, November 2017, Pages 97105. ISSN: 2454-6410 (Online).

[64] P.Pushparani, M.Valan Rajkumar, R.Suganya, "Modeling and Analysis of Maximum Power Point Tracking for Photovoltaic System using Fuzzy Logic Controller", International Journal for Science and Advance Research in Technology (IJSART), Volume 3, Issue 11, November 2017, Pages 298306. ISSN: 2395-1052 (Online)

[65] R.Suganya, M.Valan Rajkumar, P.Pushparani, "Modeling and Analysis of Sinusoidal PWM Technique for CHB Multilevel Inverter for Photovoltaic System", International Journal for Science and Advance Research in Technology (IJSART), Volume 3, Issue 11, November 2017, Pages 307-315. ISSN: 2395-1052 (Online)

[66] M.Sundaraperumal, M.Valan Rajkumar, D.Aravind, "Simulation and Analysis of APOD Pulse Width Modulation Technique for Z-Source Cascaded Multilevel Inverter for Photovoltaic System", International Journal for Science and Advance Research in Technology (IJSART),
Volume 3, Issue 11, November 2017, Pages 816824. ISSN: 2395-1052 (Online)

[67] V.Mahesh, M.Valan Rajkumar, D.Aravind, 'Improving Energy Efficiency based Aware Link Adaptation for Multiple-Input Multiple-Output OFDM Wireless Networks", International Journal of Recent Advancement in Engineering \& Research (IJRAER), Volume 3, Issue 11, November 2017, Pages 18-27. ISSN: 2456-401X (Online)

[68]S.Sathyaraj, D.Aravind, M.Valan Rajkumar, "Detection of Ventricular Fibrillation and Ventricular Tachycardia for Shockable Cardiac Arrhythmias using Slope Analysis Method", International Journal of Recent Advancement in Engineering \& Research (IJRAER), Volume 3, Issue 11, November 2017, Pages 28-36. ISSN: 2456-401X (Online)

[69] J.Eriksson, L.Girod, B.Hull, R.Newton, S.Madden, and H.Balakrishnan (2008), "The pothole patrol: Using a mobile sensor network for road surface monitoring," in proceedings of the 6th International Conference on Mobile Systems, Applications, and Services, New York, USA, pp. 29-39. 